\title{
Hemogram Abnormalities in Apparently Healthy First-time Blood Donors in Libreville, Gabon
}

\section{Cyrille Bisseye1, Jophrette Mireille Ntsame Ndong², Landry Erik Mombo, Hornéla Christine Minkoue Mambéri'1,2, Guy Mouelet Migolet², Gemael Cedrick Taty-Taty ${ }^{1}$, and Bolni Marius Nagalo ${ }^{1,3}$ \\ 1 Laboratory of Molecular and Cellular Biology (LABMC), University of Science and Technology of Masuku (USTM), P.O. Box 943, Franceville, Gabon \\ ${ }^{2}$ National Blood Transfusion Center (NBTC), P.O. Box 13895, Libreville, Gabon \\ ${ }^{3}$ Division of Hematology and Oncology, Mayo Clinic, 13400 E. Shea Blvd. Scottsdale, 85259 AZ, USA}

\section{Abstract}

Background: The objective of this study was to determine complete blood count (CBC) abnormalities in Libreville blood donors to advocate for hemoglobin pre-donation implementation and to take into account $\mathrm{CBC}$ results in blood donation qualification.

Methods: This retrospective study was conducted with 4,573 blood donors in March 2016 and from January to April 2017. CBC was performed using SysmexXP-300 ${ }^{\mathrm{TM}}$ hematology analyzer (SYSMEX Corporation, Kobe, Japan).

Results: Blood donors were predominantly males (83.7\%) with an age ranging from

Corresponding Author:

Cyrille Bisseye;

email: cbisseye@gmail.com

Received 21 February 2019

Accepted 12 May 2019

Published 30 September 2019

Production and Hosting by

Knowledge E

(c) Cyrille Bisseye et al. This article is distributed under the terms of the Creative

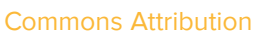

which permits

unrestricted use and

redistribution provided that

the original author and

source are credited.

Editor-in-Chief:

Prof. Mohammad A. M. Ibnouf

\section{G OPEN ACCESS}

18 to 59 yrs. The abnormalities of leukocyte, platelet, and erythrocyte counts were determined in blood donors. Leukopenia and thrombocytopenia were significantly more common in men than women $(29.02 \%$ vs $24.4 \%, p=0.011$ and $16.2 \%$ vs $7.5 \%, p<$ 0.001 ). Only $1.0 \%$ of women and $0.84 \%$ of men had leukocytosis, and $0.7 \%$ of women and $0.2 \%$ of men had thrombocytosis. Anemia was significantly more common in women compared to men (69.4\% vs $45.0 \%, p<0.001)$. Normocytic normochromic and normocytic hypochromic anemia were most common among Libreville blood donors with $39.4 \%$ and $23.6 \%$; followed by microcytic normochromic (18.7\%) and microcytic hypochromic (13.2\%) anemia. Normocytic normochromic and normocytic hypochromic anemia were significantly more common in men than in women, whereas microcytic normochromic anemia was more prevalent among women compared to men (34.6\% vs $13.9 \%, p<0.001)$.

Conclusions: The results of this study clearly show the need to perform a pre-donation hemoglobin test in blood donors and to take into account their hemogram in the blood donation selection process at the Libreville National Blood Transfusion Center.

Keywords: hemogram, anemia, blood donors, Libreville, Gabon

\section{Introduction}

Blood transfusion is a therapeutic procedure that saves lives by providing patients with the blood products they need according to their disease. It remains an essential 
component in the treatment of hemoglobinopathies, particularly sickle cell disease [1]. The stages of the transfusion chain that begin with the reception of the blood donor and end with the transfusion of the compatible blood product to the recipient are essential to observe in order to guarantee the quality of the transfused products [2]. One of these most important steps is the blood donation qualification by the transfusion physician during the pre-donation interview [3].

The qualification for blood donation is done by checking the donor for certain clinical and hematological parameters to evaluate their ability to donate. The measurement of hematological parameters in transfusion medicine is important in that it allows the detection of quantitative abnormalities of the cellular elements of the blood. However, according to the report of the transfusion research group in French-speaking Africa, the measurement of these parameters is very little done in sub-Saharan Africa during the biological testing of a blood donation [4]. The measurement of hemoglobin is the only pre-donation screening preventing the occurrence of donation-induced anemia. It also avoids bleeding in an already anemic donor.

Various factors are known to cause changes in the rate of red blood cells in an individual, such as sex, age, pregnancy, altitude, and ethnicity [5]. The measurement of hemoglobin and the assessment of anemia should be corrected taking into account ethnicity. Indeed, it has been shown that the average values of hemoglobin levels of African-American subjects are lower than those of American subjects of other ethnic origins [6]. A recent report has shown lower hemoglobin values in Africans compared to Caucasians [7]. Most blood centers perform hemoglobin testing during the pre-donation interview using the copper sulfate method in relation to its very low cost. However, previous studies have shown that anemia was observed in $42 \%$ of blood donors in Africa $[8,9]$. While progress has been observed at the National Blood Transfusion Center in Libreville in terms of reducing the post-transfusion risk of transfusion-transmissible infections, measures taken to improve the blood donation qualification during the medical interview need to be improved [10-12]. Indeed, the hematological parameters of the donor are verified post-donation and are only clinical information for the donor. The measurement of the hemoglobin level that represents the hematological parameter of eligibility for donation is not yet done during the pre-donation medical interview. This study was designed to evaluate the erythrocyte, leukocyte, and platelet counts of firsttime blood donors of Libreville to determine the prevalence and characteristics of their abnormalities. 


\section{Methods}

\subsection{Blood donors}

A cross-sectional analysis of blood donor data collected first in March 2016 and second between January and April 2017 was conducted at the National Blood Transfusion Center (NBTC). All apparently healthy voluntary non-remunerated donors (VNRD) and family/replacement donors (FRD) were selected after responding to a range of questions including medical history. Individuals aged 18 to $59 \mathrm{yrs}$ and weighing $\geq 50 \mathrm{~kg}$ were eligible for blood donations. All candidate donors responded to questions aiming at the exclusion of transfusion recipients, individuals who had jaundice or signs of hepatitis, pregnant women, and persons with unsafe sexual behavior during the six months prior to blood donation. Blood donors signed a written informed consent forms prior to blood collection. Venous blood was collected in the blood bags following standard procedures.

\subsection{Hemogram profile determination}

The complete blood count ( $\mathrm{CBC}$ ) was performed using an automated Hematology Analyzer Sysmex XP-300 ${ }^{\mathrm{TM}}$ (SYSMEX Corporation, Kobe, Japan) according to the manufacturer's instructions.

The instrument automatically counts and gives a printout result of absolute numbers of erythrocytes (RBC) $\left(10^{12} / \mathrm{L}\right)$, hemoglobin $(\mathrm{g} / \mathrm{dL})$, hematocrit $(\%), \mathrm{MCV}(\mathrm{fl}), \mathrm{MCHC}(\mathrm{g} / \mathrm{dL})$, leukocytes (WBC) $\left(10^{9} / \mathrm{L}\right)$, and platelets $\left(10^{9} / \mathrm{L}\right)$.

\subsection{Statistical analysis}

Statistical analyses were performed with the software Epilnfo version 6 and SPSS version 20; $p \leq 0.05$ was considered significant.

\section{Results}

\subsection{Demographic characteristics of the study population}

This study involved 4,573 blood donors at the NBTC in Libreville. Blood donors were predominantly males (83.7\%). The male/female sex ratio was 5/1. The age of blood 
donors ranged from 18 to 49 yrs for women and 18 to 59 yrs for men. The age groups 20-29 and 30-39 yrs were the most represented in both women (52.2\% and 34.9\%) and men (48.4\% and $35.8 \%)$ (Table 1).

TABLE 1: Repartition of blood donors by age groups.

\begin{tabular}{l|c|c|c|c|} 
& \multicolumn{3}{c}{ Female } & \multicolumn{2}{c}{ Male } \\
\hline Age groups & Number & Percentage & Number & Percentage \\
\hline$<20$ yrs & 12 & 1.6 & 37 & 1.0 \\
\hline $20-29$ yrs & 389 & 52.2 & 1,851 & 48.4 \\
\hline $30-39$ yrs & 260 & 34.9 & 1,369 & 35.8 \\
\hline $40-49$ yrs & 84 & 11.3 & 504 & 13.2 \\
\hline $50-59$ yrs & - & - & 67 & 1.8 \\
\hline Total & 745 & & 3,828 & \\
\hline
\end{tabular}

\subsection{Mean values of the blood count in blood donors}

The mean values of hematological parameters such as RBC, Hb, HCT, MCV, MCHC, WBC, and PLT are presented in Table 2. The mean values of erythrocyte parameters (RBC, Hb, HCT, and MCV) were significantly higher in men compared to women (Table 2). Only $\mathrm{MCHC}$ was higher in women compared to men $(p=0.009)$. In contrast, the mean value of PLT was significantly higher in women compared to men ( $p<0.001)$, while the WBC average was similar for both sexes $(p=0.068)$.

\subsection{Abnormalities of blood donors' blood count by gender}

The abnormalities of the hemogram of blood donors have been observed mainly in the erythrocytes. In fact, $69.4 \%$ and $84.4 \%$ of women had lower Hb and HCT levels, respectively, while $32.3 \%$ and $24.4 \%$ of them had MCV and MCHC values lower than the lower limits, respectively. Leukocyte and platelet counts showed little abnormality with $74.4 \%$ and $91.8 \%$ of female blood donors with WBC and PLT levels between baseline values (Table 3).

In male blood donors, the abnormalities of the blood count mainly concerned erythrocytes with $45 \%, 52.2 \%$ and $28.6 \%$ with $\mathrm{Hb}, \mathrm{HCT}$, and $\mathrm{MCHC}$ levels below the lower limit and only $0.2 \%, 0.5 \%$, and $1.7 \%$ of these had $\mathrm{Hb}, \mathrm{HCT}$, and $\mathrm{MCHC}$ levels above the upper limit (Table 3). With respect to leukocytes and platelets, $29.02 \%$ and $16.2 \%$ of 
TABLE 2: Comparison of mean values of complete blood count (CBC) in female and male blood donors.

\begin{tabular}{|c|c|c|c|}
\hline Hematological parameters & Female & Male & \\
\hline & Mean $\pm S D$ & Mean \pm SD & $P$-value* \\
\hline $\mathrm{RBC} \times 10^{12} / \mathrm{L}$ & $4.049 \pm 0.531$ & $4.878 \pm 7.425$ & $<0.001$ \\
\hline $\mathrm{Hb}(\mathrm{g} / \mathrm{dL})$ & $10.802 \pm 1.478$ & $13.092 \pm 1.538$ & $<0.001$ \\
\hline HCT (\%) & $32.860 \pm 4.433$ & $39.813 \pm 4.538$ & $<0.001$ \\
\hline $\operatorname{MCV}(f \mathrm{~L})$ & $81.294 \pm 8.261$ & $84.586 \pm 6.953$ & $<0.001$ \\
\hline $\mathrm{MCHC}(\%)$ & $32.977 \pm 2.804$ & $32.975 \pm 2.708$ & 0.009 \\
\hline WBC $\times 10^{9} / \mathrm{L}$ & $5.035 \pm 1.911$ & $4.915 \pm 1.512$ & 0.068 \\
\hline $\mathrm{PLT} \times 10^{9} / \mathrm{L}$ & $239.168 \pm 68.931$ & $203.015 \pm 59.690$ & $<0.001$ \\
\hline
\end{tabular}

TABLE 3: Distribution of erythrocyte, leukocyte, and platelet parameters of female versus male blood donors according to Reference and threshold values.

\begin{tabular}{|c|c|c|c|c|c|c|c|}
\hline \multirow[t]{2}{*}{$\begin{array}{l}\text { Hematolog- } \\
\text { ical } \\
\text { parameters }\end{array}$} & \multirow[t]{2}{*}{ Reference values } & \multicolumn{2}{|c|}{$\begin{array}{l}\text { Number of female vs } \\
\text { male donors whose } \\
\text { value is below the } \\
\text { lower limit }\end{array}$} & \multicolumn{2}{|c|}{$\begin{array}{l}\text { Number of female vs } \\
\text { male donors whose } \\
\text { value is in the } \\
\text { reference range }\end{array}$} & \multicolumn{2}{|c|}{$\begin{array}{l}\text { Number of female } \\
\text { vs male donors } \\
\text { whose value is } \\
\text { greater than the } \\
\text { upper limit }\end{array}$} \\
\hline & & Numbers & $\%$ & Numbers & $\%$ & Numbers & $\%$ \\
\hline $\mathrm{RBC}\left(\times 10^{12} / \mathrm{L}\right)$ & $\begin{array}{l}\mathrm{F}: 4<\mathrm{RBC}<5.3 \\
\mathrm{M}: 4.2<\mathrm{RBC}<5.7\end{array}$ & 359/707 & 48.2/18.5 & $359 / 2859$ & $48.2 / 74.7$ & $27 / 262$ & $3.6 / 6.8$ \\
\hline $\mathrm{Hb}(\mathrm{g} / \mathrm{dL})$ & $\begin{array}{l}F: 12<\mathrm{Hb}<16 \\
M: 13<\mathrm{Hb}<18\end{array}$ & $517 / 1724$ & $69.4 / 45.0$ & $224 / 2098$ & $30.0 / 54.8$ & $4 / 6$ & $0.6 / 0.2$ \\
\hline HCT (\%) & $\begin{array}{l}F: 37<H C T<46 \\
M: 40<H C T<52\end{array}$ & 629/1998 & $84.4 / 52.2$ & $112 / 1812$ & $15.0 / 47.3$ & $4 / 18$ & $0.5 / 0.5$ \\
\hline $\mathrm{MCV}(\mathrm{fL})$ & $80 \leq \mathrm{MCV} \leq 100$ & $241 / 494$ & $32.3 / 12.9$ & 498/3302 & $66.8 / 86.3$ & $6 / 32$ & $0.8 / 0.8$ \\
\hline $\mathrm{MCHC}(\%)$ & $32 \leq \mathrm{MCHC} \leq 36$ & $182 / 1094$ & $24.4 / 28.6$ & $527 / 2669$ & 70.7/69.7 & $36 / 65$ & $4.8 / 1.7$ \\
\hline WBC (x 109/L) & $4<W B C<10$ & 183/1111 & 24.6/29.02 & $554 / 2685$ & 74.4/70.14 & $8 / 32$ & $1.0 / 0.84$ \\
\hline PLT (x 109/L) & $150<\mathrm{PLT}<450$ & $56 / 620$ & 7.5/16.2 & 684/3199 & 91.8/83.6 & $5 / 9$ & $0.7 / 0.2$ \\
\hline
\end{tabular}

men had WBC and PLT counts below the lower limit and only $0.84 \%$ and $0.2 \%$ of these showed WBC and PLT rates above the upper limit (Table 3). 


\subsection{Comparison of blood count abnormalities in blood donors by gender}

The three hematological parameters that have been taken into account are hemoglobin level (anemia), white blood cells (leukopenia and leukocytosis), and platelets (thrombocytopenia and thrombocytosis). The results show that women were significantly more frequently anemic than men $(69.4 \%$ vs $45 \%, p<0.001)$, while leukopenia and thrombocytopenia were significantly more common in men than women $(29.02 \%$ vs $24.4 \%, p=0.011$ and $16.2 \%$ vs $7.5 \%, p<0.001$ ) (Table 4 ). Only $1.0 \%$ of women and $0.84 \%$ of men had leukocytosis, and $0.7 \%$ of women and $0.2 \%$ of men had thrombocytosis (Table 4).

TABLE 4: Comparison of erythrocytes, leucocytes, and platelets abnormalities in blood donors by gender.

\begin{tabular}{|c|c|c|c|c|c|}
\hline \multirow[b]{2}{*}{ Hematological parameters } & \multicolumn{2}{|c|}{ Female } & \multicolumn{2}{|c|}{ Male } & \multirow[b]{2}{*}{ P-value } \\
\hline & Number & Percentage & Number & Percentage & \\
\hline Hb (Female: $\mathrm{Hb}<12$; Male: $\mathrm{Hb}<13$ ) & 517 & 69.4 & 1,742 & 45.0 & $<0.001$ \\
\hline \multicolumn{6}{|l|}{ WBC } \\
\hline Leukopenia (WBC $\left.<4 \times 10^{9} / \mathrm{L}\right)$ & 182 & 24.4 & 1,111 & 29.02 & 0.011 \\
\hline Leukocytosis (WBC > $\left.10 \times 10^{9} / \mathrm{L}\right)$ & 8 & 1.0 & 32 & 0.84 & 0.778 \\
\hline \multicolumn{6}{|l|}{ PLT } \\
\hline Thrombocytopenia (PLT < $\left.150 \times 10^{9} / \mathrm{L}\right)$ & 56 & 7.5 & 620 & 16.2 & $<0.001$ \\
\hline Thrombocytosis (PLT < $\left.450 \times 10^{9} / \mathrm{L}\right)$ & 5 & 0.7 & 9 & 0.2 & 0.073 \\
\hline
\end{tabular}

\subsection{Characterization of different levels and types of anemia in Libreville blood donors}

Anemia was significantly more frequent in women compared to men in the age groups $<20$ yrs and $20-29$ yrs ( $2.0 \%$ vs $1.1 \%, p=0.039$ and $52.6 \%$ vs $46.7 \%, p=0.002$ ) (Table 5). In contrast, among blood donors aged 40 to 49 years, anemia was more prevalent in men compared to women (16.1\% vs $11.2 \%, p<0.001)$.

With regard to the degree of anemia, slight anemia predominated in both women (63.2\%) and men (84.8\%). Severe or moderate anemia was observed in $4.3 \%$ and $32.5 \%$ of women and $1.3 \%$ and $13.9 \%$ of men, respectively. They were significantly more frequent in women compared to men $(p<0.001$ and $p<0.001)$ (Table 5). 
TABLE 5: Comparison of anemia level among blood donors by gender and age.

\begin{tabular}{|c|c|c|c|c|c|c|}
\hline \multicolumn{3}{|c|}{ Female with anemia } & \multicolumn{3}{|c|}{ Male with anemia } & \multirow[b]{2}{*}{ P-value } \\
\hline Parameters & Number & $\%$ & Parameters & Number & $\%$ & \\
\hline \multicolumn{7}{|l|}{ Age groups } \\
\hline$<20$ yrs & 10 & 2 & $<20 y r s$ & 19 & 1.1 & 0.039 \\
\hline $20-29$ yrs & 272 & 52.6 & 20-29yrs & 802 & 46.5 & 0.002 \\
\hline 30-39 yrs & 177 & 34.2 & 30-39yrs & 586 & 34 & 0.91 \\
\hline $40-49$ yrs & 58 & 11.2 & $40-49 y r s$ & 278 & 16.1 & $<0.001$ \\
\hline $50-59$ yrs & - & - & 50-59yrs & 39 & 2.3 & \\
\hline \multicolumn{7}{|l|}{ Anemia level } \\
\hline Severe $(\mathrm{Hb}<8)$ & 22 & 4.3 & Severe $(\mathrm{Hb}<9)$ & 22 & 1.3 & $<0.001$ \\
\hline Mild $(8<\mathrm{Hb}<10)$ & 168 & 32.5 & Mild $(9<\mathrm{Hb}<11)$ & 240 & 13.9 & $<0.001$ \\
\hline Slight $(10<\mathrm{Hb}<12)$ & 327 & 63.2 & Slight $(11<\mathrm{Hb}<13)$ & 1,462 & 84.8 & $<0.001$ \\
\hline
\end{tabular}

Normocytic normochromic and normocytic hypochromic anemia were most common among Libreville blood donors with $39.4 \%$ and $23.6 \%$, respectively. They were followed by microcytic normochromic (18.7\%) and microcytic hypochromic (13.2\%) anemia. All types of hyperchromic anemia were found in 3.4\% (77/2241) of blood donors. The different types of anemia were not associated with age of the blood donors (Table 6). Microcytic normochromic anemia was significantly more frequent in female blood donors compared to male blood donors $(p<0.001$ ). While normocytic hypochromic or normochromic anemia were more prevalent in men than in women $(p<0.001$ and $p<$ 0.001) (Table 6)

\section{Discussion}

This study was conducted with the aim of improving the qualification criteria for blood donation at the NBTC located in Libreville by including the results of the CBC in the transfusion process. The measurement of hematological parameters in blood donors by $\mathrm{CBC}$ allows the diagnosis of certain existing blood abnormalities in the donor to establish a first barrier against transmitted-transfusion infections. In Libreville blood donors, we observed that red cell parameters (RBC, $\mathrm{Hb}, \mathrm{HCT}$, and $\mathrm{MCV}$ ) were higher in men compared to women. The mean of WBC was similar for both sexes. In contrast, the mean of PLT was higher among women than men which is in agreement with previous 
TABLE 6: Comparison of anemia type among blood donors by gender and age.

\begin{tabular}{|c|c|c|c|c|c|c|c|c|c|}
\hline & \multicolumn{9}{|c|}{ Type of anemia } \\
\hline & MAHA & МАНуA & MANA & MIHA & MIHyA & MINA & $\mathrm{NHA}$ & NHyA & NNA \\
\hline & N (\%) & N (\%) & N (\%) & $\mathrm{N}(\%)$ & N (\%) & N (\%) & $\mathrm{N}(\%)$ & $\mathrm{N}(\%)$ & $\mathrm{N}(\%)$ \\
\hline \multicolumn{10}{|l|}{ Gender } \\
\hline Female & $0(0.0)$ & $6(1.2)$ & $0(0.0)$ & $5(1.0)$ & 57 (11.0) & 179 (34.6) & $7(1.4)$ & 93 (18.0) & $170(32.9)$ \\
\hline Male & $1(0.1)$ & $28(1.6)$ & $3(0.2)$ & $15(0.9)$ & 239 (13.9) & 240 (13.9) & 49 (2.8) & $435(25.2)$ & 714 (41.4) \\
\hline P-value & NC & NS & $\mathrm{NC}$ & NS & NS & $<0.001$ & NS & $<0.001$ & $<0.001$ \\
\hline \multicolumn{10}{|l|}{ Age groups } \\
\hline$<20$ yrs & $0(0.0)$ & $0(0.0)$ & $0(0.0)$ & $1(3.4)$ & $3(10.3)$ & $8(27.6)$ & $1(3.4)$ & $8(27.6)$ & $8(27.6)$ \\
\hline $20-29$ yrs & $0(0.0)$ & $17(1.6)$ & $1(0.1)$ & $12(1.1)$ & 147 (13.7) & 211 (19.6) & $28(2.6)$ & $231(21.5)$ & 427 (39.8) \\
\hline 30-39 yrs & $0(0.0)$ & $9(1.2)$ & $1(0.1)$ & $4(0.5)$ & 87 (11.4) & 148 (19.4) & $17(2.2)$ & $188(24.6)$ & 309 (40.5) \\
\hline 40-49 yrs & $1(0.3)$ & $6(1.8)$ & $1(0.3)$ & $3(0.9)$ & $56(16.7)$ & 47 (14.0) & $9(2.7)$ & 87 (25.9) & $126(37.5)$ \\
\hline $50-59$ yrs & $0(0.0)$ & $2(5.1)$ & $0(0.0)$ & $0(0.0)$ & $3(7.7)$ & $5(12.8)$ & $1(2.6)$ & $14(35.9)$ & 14 (35.9) \\
\hline P-value & NC & NS & NC & NS & NS & NS & NS & NS & NS \\
\hline
\end{tabular}

MAHA: Macrocytic hyperchromic anemia; MAHyA: Macrocytic hypochromic anemia; MANA: Macrocytic normochromic anemia; MIHA: Microcytic hyperchromic anemia; MIHyA: Microcytic hypochromic anemia; MINA: Microcytic normochromic anemia; NHA: Normocytic hyperchromic anemia; NHyA: Normocytic hypochromic anemia; NNA: Normocytic normochromic anemia.

studies [13-15]. The mean values of red cell parameters vary with age and sex [16]. Indeed, values are higher in men compared to women, which is in agreement with the results of a recent report [7]. On the other hand, no difference between women and men was found for the leukocyte count as previously reported [17, 18]. Leukocyte, platelet, and erythrocyte abnormalities of blood donors were assessed. CBC of blood donors showed that $70.8 \%$ of these showed no leucocyte abnormality. However, leukopenia was the most frequently observed WBC abnormality with a prevalence of $28.3 \%$. Two previous studies in Nigeria and Cameroon reported the prevalence of leukopenia of $12.5 \%$ and $14.96 \%$ in blood donors $[19,20]$. Leukopenia was significantly more prevalent in men than in women.

Leukocytosis was present in only $0.9 \%$ of Libreville blood donors, while it was the most observed leukocyte abnormality in Morocco with 5.27\% [18].

With respect to platelet count, $84.9 \%$ of blood donors had no platelet count abnormalities. Thrombocytopenia (14.8\%) was the most observed abnormality compared to thrombocytosis $(0.3 \%)$. Thrombocytopenia was significantly higher in men compared to 
women. Thrombocytopenia may be central or peripheral due to destruction or excessive consumption of platelets. In this study, thrombocytosis was higher in women than in men as reported previously $[21,22]$. But the difference observed was not significant. The observed thrombocytosis may be due in part to infections or iron deficiency [23].

With regard to the erythrocyte, anemia was found in $49 \%$ of blood donors. The prevalence of anemia found in our study is significantly higher than those of $36.5 \%$ and 28\% observed, respectively, in Congo and Cameroon [20, 24]. Lower anemia prevalences of $8.6 \%$ has been reported in North Africa, particularly in Tunisia [25]. The most anemic age group was 20 to 29 yrs, with rates of $52.6 \%$ and $46.5 \%$, respectively, for women and men. In Morocco, anemia rates of $43.5 \%$ and $42.5 \%$ were reported in the age group 30-39 yrs for both women and men [18]. In Congo, however, the prevalence of anemia was higher in the $40-49$ age group, with $42.7 \%$ in both sexes [24]. The high prevalence of anemia found in this study could be explained by the high prevalence of hemoglobinopathies in Gabon such as alpha and beta thalassemias, sickle cell anemia, and Glucose-6-Phosphate Deshydrogenase deficiency [26-28].

In this study, we found that women (69.4\%) were more frequently anemic than men (45.0\%). Many studies in Africa have also reported variable prevalence of anemia among women ranging from $49 \%$ in Tanzania to $16.9 \%$ in Tunisia $[25,29]$. Slight anemia was found in $84.8 \%$ of men and $63.2 \%$ of women. These results suggest that anemia, according to thresholds established by the $\mathrm{WHO}$, is probably well tolerated by blood donors in Gabon as few adverse events following blood donation in Libreville have been reported among blood donors. Therefore, it could be more appropriate to establish threshold hemoglobin values specific to the Gabonese population in particular and to populations of color in sub-Saharan Africa in general to define anemia.

In this study, the most common anemias in Libreville blood donors were normocytic normochromic (39.4\%) and normocytic hypochromic (23.6\%). The highest prevalence of normocytic normochromic anemia observed in Libreville blood donors is consistent with the prevalence of $46.74 \%$ reported previously in Ghana [30]. The distribution of these two types of anemia was not identical in both sexes. Normocytic normochromic and normocytic hypochromic anemia were significantly more frequent in men than in women.

In contrast of the studies of Bakrim et al. in Morocco and Nzengu-Lukusa in Democratic Republic of Congo (DRC) [18, 24], who found high prevalence of microcytic anemia in blood donors, we observed microcytic normocytic and microcytic hypochromic anemia, respectively, in $18.7 \%$ and $13.2 \%$ of blood donors. Microcytic normochromic anemia 
was significantly more frequent in women (34.6\%) than men (13.9\%). In this study, we did not perform iron assessment. However, the prevalence of 13.2\% microcytic hypochromic anemia observed in Libreville blood donors may be associated with iron deficiency. Indeed, previous studies in Burkina Faso, Tunisia, and India have shown the association between microcytosis and Iron deficiency anemia [25, 31, 32].

\section{Conclusion}

The aim of this study was to provide reliable data to advocate for pre-donation hemoglobin measurement in Libreville blood donors and to take into account CBC results in blood donation qualification. It appears that blood count abnormalities frequently encountered in blood donors were leucopenia, thrombocytopenia, and normocytic normochromic anemia. Since anemia is present in about half of the blood donor population, a specific hemoglobin threshold in Gabon from which a donation could be authorized should be defined.

\section{Ethical Approval}

This study was approved by the CNTS Ethics Committee.

\section{Acknowledgments}

The authors would like to thank all the participants of this study, the CNTS' staff Ripaire Mboumba and JPA for critically reading the manuscript.

\section{Funding}

The authors are grateful to the NBTC for its financial support through le programme de support à la recherche.

\section{Conflict of Interest}

The authors declare that there is no conflict of interest. 


\section{References}

[1] de Montalembert, M. (2004). Transfusion sanguine et hémoglobinopathies. Hématologie, vol. 10, pp. 470-478.

[2] Kabinda Maotela, J., Ramazani, S. Y., Misingi, P., et al. (2015). Blood transfusion in the Democratic Republic of Congo: efforts and challenges. Médecine et Santé Tropicales, vol. 25, no. 4, pp. 342-349.

[3] Tagny, C. T., Murphy, E. L., Lefrere, J. J., et al. (2013). The Francophone Africa Blood Transfusion Research Network: a five-year report (2007-2012). Transfusion Medicine, vol. 23, no. 6, pp. 442-444.

[4] Tagny, C. T., Owusu-Ofori, S., Mbanya, D., et al. (2010). The blood donor in subSaharan Africa: a review. Transfusion Medicine, vol. 20, no. 1, pp. 1-10.

[5] Anaes. (1997). Lecture critique de l'hémogramme: valeurs seuils à reconnaître comme probablement pathologiques et principales variations non pathologiques. Service des Références Médicales, pp. 1-37.

[6] Qiao, R., Yang, S., Yao, B., et al. (2014). Complete blood count reference intervals and age- and sex-related trends of North China Han population. Clinical Chemistry and Laboratory Medicine, vol. 52, no. 7, pp. 1025-1032.

[7] Omuse, G., Maina, D., Mwangi, J., et al. (2018). Complete blood count reference intervals from a healthy adult urban population in Kenya. PLOS ONE, vol. 13, no. 6, pp. e0198444.

[8] World Health Organization. (2015). The global prevalence of anaemia in 2011. Geneva: World Health Organization.

[9] World Health Statistics. (2016). Monitoring health for the SDGs indicators of overall progress. Tables of health statistics by country, WHO region and globally en_whs201 _annexB ( World Health Organization 2016.

[10] Rerambiah, L. K., Rerambiah, L. E., Bengone, C., et al. (2014). The risk of transfusiontransmitted viral infections at the Gabonese National Blood Transfusion Centre. Blood Transfusion, vol. 12, no. 3, pp. 330-333.

[11] Eko Mba, J. M., Ntsame Ndong, M. J., and Bisseye, C. (2017). Caractéristiques sociodémographiques associées au risque de transmission du $\mathrm{VIH}$, du $\mathrm{VHC}$ et de Treponema pallidum par les donneurs de sang de premier don de Libreville (Gabon): dynamique trisannuelle des infections de 2009 à 2015. International Journal of Biological and Chemical Sciences, vol. 11, no. 1, pp. 350-359. 
[12] Eko Mba, J. M., Bisseye, C., Ntsame Ndong, J. M., et al. (2018). Prevalent hepatitis B surface antigen among first-time blood donors in Gabon. PLOS ONE, vol. 13, no. 4, pp. e0194285.

[13] Stevens R. F. and Alexander M. K. (1977). A sex difference in the platelet count. British Journal of Haematology, vol. 37, pp. 295-300.

[14] Bain B. J.. Platelet count and platelet size in males and females. (1985). Scandinavian Journal of Haematology, vol. 35, no. 1, pp. 77-79.

[15] Lozano, M., Narvaez, J., Faundez, A., et al. (1998). Platelet count and mean platelet volume in the Spanish population. Medicina Clínica, vol. 110, no. 20, pp. 774-777.

[16] Lainey E., Boirie M., and Fenneteau, O. (2006). Hémogramme en pédiatrie: variations physiologiques. Revue francophone des laboratoires, vol. 2009, no. 416, pp. 49-59.

[17] Du, Y., Chen, H., Sun, H., et al. (2016). Investigation and analysis of reference intervals for blood cell parameters in a healthy population from daxingan region inner mongolia. Clinical Laboratory, vol. 62, no. 1-2, pp. 129-134.

[18] Bakrim, S., Ouarour, A., Jaidann, K., et al. (2018). Hemogram profile and interest of pre-donation hemoglobin measurement in blood donors in the northwest region of Morocco. Transfusion Clinique et Biologique, vol. 25, no. 1, pp. 35-43.

[19] Jeremiah, Z. A., Umoh, R. E., and Adias, T. C. (2011). Subclinical leukopenia in a cross section of Nigerian blood donors. Journal of Blood Medicine, vol. 2, pp. 79-85.

[20] Kourouma, K., Ndanchi Tiotdia, A., Kanmangne, F., et al. (2015). Profil de l'hémogramme chez les donneurs de sang à l'Ouest du Cameroun. Transfusion Clinique et Biologique, vol. 22, pp. 215-272.

[21] Biino, G., Santimone, I., Minelli, C., et al. (2013). Age- and sex-related variations in platelet count in Italy: a proposal of reference ranges based on 40987 subjects' data. PLOS ONE, vol. 8, no. 1, pp. e54289.

[22] Bakrim, S., Motiaa, Y., Benajiba, M., et al. (2018). Establishment of the hematology reference intervals in a healthy population of adults in the Northwest of Morocco (Tangier-Tetouan region). Pan African Medical Journal, vol. 29, pp. 169.

[23] Serraj, K., Mecili, M., Azzouzi, H., et al. (2012). Les thrombocytoses: physiopathologie, diagnostic et traitement. Médecine Thérapeutique, vol. 18, pp. 11-20.

[24] Nzengu-Lukusa, F., Yuma-Ramazani, S., Sokolua-Mvika, E., et al. (2016). Iron deficiency and anemia among donors in Kinshassa. Pan African Medical Journal, vol. 23, pp. 174.

[25] Toumi, N. H., Najjar, M. F., and Boukef, K. (1992). Blood donors and anemia. Revue Française de Transfusion et d'Hémobiologie, vol. 35, no. 4, pp. 295-298. 
[26] Mombo, L. E., Ntoumi, F., Bisseye, C., et al. (2003). Human genetic polymorphisms and asymptomatic Plasmodium falciparum malaria in Gabonese schoolchildren. The American Journal of Tropical Medicine and Hygiene, vol. 68, no. 2, pp. 186-190.

[27] Nguetse, C. N., Meyer, C. G., Adegnika, A. A., et al. (2016). Glucose-6-phosphate dehydrogenase deficiency and reduced haemoglobin levels in African children with severe malaria. Malaria Journal, vol. 15, no. 1, pp. 346.

[28] Mombo, L. E., Mabioko-Mbembo, G., Kassa-Kassa, R. F., et al. (2017). Haemoglobin F, $A 2$, and $S$ levels in subjects with or without sickle cell trait in south-eastern Gabon. Hematology, vol. 22, no. 8, pp. 508-513.

[29] Massawe, S. N., Urassa, E. N., Nystrom, L., et al. (2002). Anaemia in women of reproductive age in Dar-es-Salaam, Tanzania. East African Medical Journal, vol. 79, no. 9, pp. 461-466.

[30] Antwi-Baffour, S., Annor, D. K., Adjei, J. K., et al. (2015). Anemia in prospective blood donors deferred by the copper sulphate technique of hemoglobin estimation. BMC Hematology, vol. 15, p. 15.

[31] Nacoulma, E. W., Sakande, J., Ouermi, A., et al. (2008). Causes of iron-deficiency anaemia in the internal medecine department of the national teaching hospital of Ouagadougou. Sante, vol. 18, no. 4, pp. 223-225.

[32] Tiwari, A. K., Chandola, I., and Ahuja, A. (2010). Approach to blood donors with microcytosis. Transfusion Medicine, vol. 20, no. 2, pp. 88-94. 